\title{
SYNDROMAL CHARACTERISTICS OF DEPRESSIVE MANIFESTATIONS IN PATIENTS WITH COGNITIVE IMPAIRMENTS AT DEPRESSIVE DISORDERS
}

\author{
Yaroslavtsev S., Kalenska G. \\ Kherson Regional Institute for Psychiatric Care \\ https://doi.org/10.35339/ic.7.3.152-156
}

\begin{abstract}
362 patients with cognitive impairment at depressive disorders were examined, of them 123 patients with recurrent depressive disorder (RDD), 141 patients with bipolar affective disorder (BAD) and 98 patients with prolonged depressive reaction (PDR). Differentiated clinical and psychopathological features of patients with cognitive impairment at depressive disorders were established: 1) combination of apathetic-adynamic, astheno-energetic and anxious symptom complexes; predominance of moderate and major depressive episodes; severity of apathy, subjective and objective signs of depression, decrease in concentration and ability to feel were determined in patients with RDD; 2) combination of astheno-energetic, apathetic-adynamic, and melancholic symptom complexes; predominance of moderate and major depressive episodes; the severity of apathy, subjective signs of depression, suicidal thoughts, insomnia and decrease in concentration in patients with BAD; 3) combination of anxious and apathetic-adynamic symptom complexes; the predominance of moderate and minor depressive episodes; the severity of internal stress, apathy, suicidal thoughts and loss of appetite in patients with PDR.

Keywords: patients with cognitive impairment, depressive disorders, clinical and psychopathological features, recurrent depressive disorder, bipolar depressive disorder, prolonged depressive reaction.
\end{abstract}

\section{Introduction}

The relevance of the clinical study of depressive disorders is associated with the high prevalence of depression in both psychiatric and general somatic practice, involving $10 \%$ of the population [1]. $20 \%$ of women and $10 \%$ of men experience a depressive episode during their lifetime [1-3].

According to the WHO, in the recent decade depression has become not only a medical but also a social problem that needs to be addressed due to such adverse effects as a significant reduction in the social functioning of these patients, suicide problems, and finally significant economic disability losses. $[1,4,5]$. The increase in the number of affective, in particular, depressive states, is associated with a number of factors: an increase in the number of affective disorders,

Corresponding Author:

Kalenska Galyna-MD, Senior scientific fellow, $\mathrm{PhD}$ in Psychology. SI "Institute of neurology, psychiatry and narcology NAMN of Ukraine", Kharkiv, Ukraine.E-mail: kalenskaya galina@ukr.net pathomorphosis of mental illnesses occurring at milder psychopathological levels, tendencies of mental disorders to somatization with complex autonomic and visceral disorders and maladaptation [6].

It should be noted that there are significant difficulties in providing medical and rehabilitation care for the patients with depression. Thus, duration of depressive episodes today is from 3 to 5 years $[2,5,7]$. Proper diagnosis and administration of antidepressants takes place on an average two years after the onset of depression $[1,8-10]$. The share of depression in patients who seek help in general medical institutions of outpatient and hospital network, ranges from $10 \%$ to $22-33 \%$, and only in $10-30 \%$ of cases depressive disorders are recognized as such by general practitioners $[4,7,9,11]$. In most cases, depression has a chronic long-term course. According to the level of disability, the population of patients with depression exceeds the population of patients with schizophrenia $[5,12]$. The difficulties in recognizing depression at the initial stage of the disease can be explained by variety of somatic complaints that 
hide affective pathology. Adequate clinical evaluation is important both for the prognosis of depressive disorder and for the choice of effective therapy. Therefore, investigation aimed at clarifying the differential clinical and psychopathological features of anxiety and depressive manifestations in patients with cognitive impairment $(\mathrm{CI})$ at depressive disorders (DD) is relevant and can improve diagnostic criteria and effectiveness of treatment of different types of DD.

\section{Purposes, subjects and methods:}

2.1. Purpose of the study was to identify the clinical and psychopathological features of the leading symptom complexes and severity of depressive manifestations in patients with cognitive impairment at different types of depressive disorders.

\subsection{Subjects \& Methods}

The study involved 362 patients with CI at DD: 123 patients with recurrent depressive disorder (RDD), 141 patients with bipolar affective disorder (BAD) and 98 patients with prolonged depressive reaction (PDR).

The study used an integrated approach, which consisted of the use of clinical-psychopathological, psychometric (Montgomery-Asberg Depression Rating Scale (MADRS)) and statistical methods [13]. Statistical data processing was used to determine the average values of quantitative parameters, their standard errors (in the format $\% \pm \mathrm{m} \%$ ), the reliability of differences (StudentFisher criteria [ $\mathrm{t}]$, Kolmogorov-Smirnov $[\lambda]$ ). Statistical processing of the results was performed using Excel-2010 and STATISTICA 6.1.

\section{Conflict of interests}

There is no conflict of interests. We certificate that we do not have any financial or personal relationships that might bias the content of this work.

\section{Results \& Discussion}

The group of the patients with RDD consisted of 57 men ( $46.34 \pm 2.78) \%$ and 66 women (53.66 $\pm 2.99) \%$, that with BAD -76 men $(53.90 \pm 2.61)$ $\%$ and 65 women $(46.10 \pm 2.42) \%$, with PDR 43 men (43.88 \pm 3.39$) \%$ and 55 women $(56.12$ $\pm 3.83) \%$, which is generally consistent with the typical distribution by sex in DD. That is, women predominated $(51.96 \%, \mathrm{DC}=0.66, \mathrm{MI}=0.02$, $\mathrm{p}=0.046$ ), only in the group of patients with $B A D$ there were more men $(53.90 \%, \mathrm{DC}=0,66, \mathrm{MI}=$ $0.02, p=0.046)$. The predominant number of patients with CI in DD was characterized by the age of 30-44 years $(38.12 \%)$. There were more young people (18-29 years) among patients with $\operatorname{PDR}(21.43 \%, \mathrm{DC}=8.19, \mathrm{MI}=0.74, \mathrm{p}=0.0001)$ and among patients with BAD $(31.21 \%, \mathrm{DC}=$ 9.82, $\mathrm{MI}=1.37, \mathrm{p}=0.0001)$, and middle-aged people (45-59 years old) and elderly people (6065 years old) among patients with RDD $(37.40 \%$, $\mathrm{DC}=1.54, \mathrm{MI}=0.09, \mathrm{p}=0.016$ and $17.07 \%$, $\mathrm{DC}=4.78, \mathrm{MI}=0.27, \mathrm{p}=0.002$ ).

Differentiated analysis of syndromal variants of depressive disorder in patients with cognitive impairment is presented in Figure 1.

Invetigation of the leading type of affect revealed that apathetic-dynamic $(27.64 \pm 1.93)$ $\%$, astheno-energetic $(26.83 \pm 1.88) \%$, anxious $(13.01 \pm 0,99) \%$ and senesto-hypochondriac $(11.38 \pm 0.88) \%$ symptom complexes dominated in the patients with RDD. The prevalence of dreary $(5.69 \pm 0.45) \%$, dysphoric $(7.32 \pm 0.58)$ $\%$ and obsessive-depressive $(8.13 \pm 0.64) \%$ of symptom complexes was significantly lower.

Analysis of the syndromal structure of depressive disorders in BAD allowed to determine

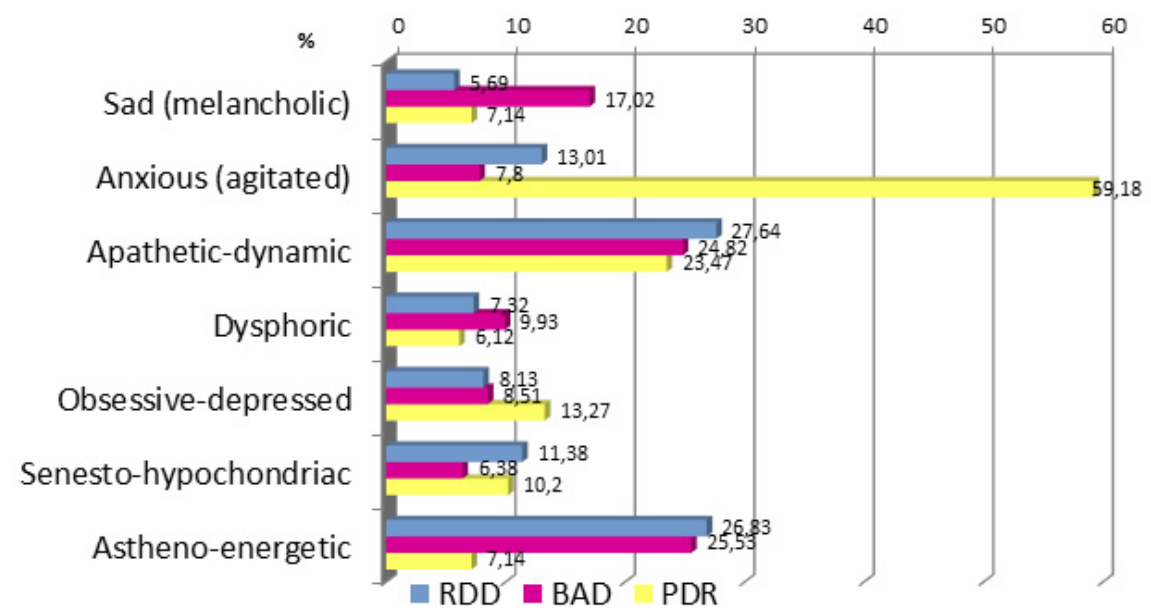

Fig. 1. Syndromal variants of depressive manifestations in patients with cognitive impairment at depressive disorders 
the predominance of astheno-energetic $(25.53 \pm$ $1.57) \%$, apathetic-dynamic $(24.82 \pm 1.54) \%$ and melancholic $(17.02 \pm 1.11) \%$ syndromes. depressive episode $(36.59 \pm 2.39) \% ; 34.96 \%$ of persons had a major depressive episode and $28.46 \%$ of patients had a small depressive episode (Fig. 2).

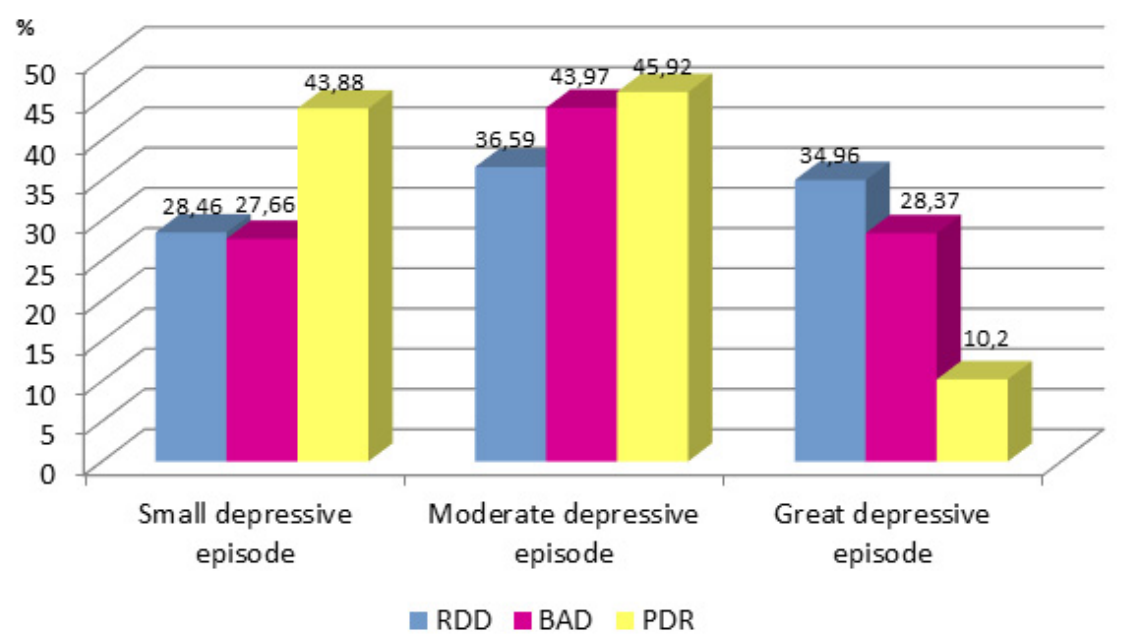

Fig. 2. Severity of depression in patients with cognitive impairment at depressive disorders (MADRS)

Senesto-hypochondric $(6.38 \pm 0.44) \%$, agitated $(7.80 \pm 0.54) \%$, obsessive-depressive $(8.51 \pm$ $0.58) \%$ and dysphoric $(9.93 \pm 0.67) \%$ symptom complexes were significantly less common.

In patients with PDR, the first place among the typical affective syndromes is occupied by anxiety $(59.18 \pm 3.90) \%$, as well as apatheticdynamic $(23.47 \pm 2.12) \%$, obsessive-depressive (13.27 \pm 1.27$) \%$ and senesto-hypochondriac $(10.20 \pm 1.00) \%$ syndromes. The least common were dysphoric $(6.12 \pm 0.61) \%, \operatorname{sad}(7.14 \pm 0.71) \%$ and astheno-energetic $(7.14 \pm 0.71) \%$ syndromes.

Statistical analysis of the syndromal structure of depressive disorders showed that the patients with BAD had a more pronounced sadness syndrome $(17.02 \pm 1.11) \%$, compared with the patients with RDD and PDR $(5.69 \%, \mathrm{DC}=4.76$, $\mathrm{MI}=0.27, \mathrm{p}<0.0023$ and $7.14 \%, \mathrm{DC}=3.77$, $\mathrm{MI}=0.19, \mathrm{p}<0.0124$, respectively). The patients with PDR had a more pronounced anxiety syndrome $(59.18 \pm 3.90) \%$ compared with patients with RDD and BAD (13.01\%, DC = 6.58, $\mathrm{MI}=1.52, \mathrm{p}<0.0001$ and $7.80 \%, \mathrm{DC}=$ $8.80, \mathrm{MI}=2.26, \mathrm{p}<0.0001)$ and the least pronounced astheno-energetic syndrome $(7.14 \pm$ $0.71) \%$, which was more characteristic of the patients with $\mathrm{RDD}(26.83 \%, \mathrm{DC}=5.75, \mathrm{MI}=$ $0.57, \mathrm{p}<0.0001)$ and $\operatorname{BAD}(28.57 \%, \mathrm{DC}=5.53$, $\mathrm{MI}=0.51, \mathrm{p}<0.0001)$.

The clinical and psychopathological method was supplemented by psychometric scales for assessing depression MADRS, the results of which allowed determining that among patients with RDD dominated the persons with a moderate
Among patients with $\mathrm{BAD}$, the vast majority of people had a moderate severity of depressive episode $(43.97 \pm 2.35) \%, 28.37 \%$ of patients had a major depressive episode and $27.66 \%$ had a minor depressive episode. The patients with moderate $(45.92 \pm 3.48) \%$ and minor $(43.88 \pm$ $3.38) \%$ depressive episodes predominated among patients with PDR, only $10.20 \%$ of them were diagnosed with major depressive episode. The conducted statistical analysis allowed to establish that the patients with a small depressive episode predominated among persons with PDR $(43.88 \pm 3.38) \%$ than among patients with RDD $(28.46 \%, \mathrm{DC}=1.88, \mathrm{MI}=0,15, \mathrm{p}<0.0068)$ and $\operatorname{BAD}(27.66 \%, \mathrm{DC}=2.00, \mathrm{MI}=0.16, \mathrm{p}<0.0039)$, in which there were more patients with a major depressive episode $(34.96 \%$ and $28.37 \%$, respectively) compared with the patients with $\operatorname{PDR}(10.20 \%, \mathrm{DC}=5.35, \mathrm{MI}=0.66, \mathrm{p}<0.0001$ and $\mathrm{DC}=4.44, \mathrm{MI}=0.40, \mathrm{p}<0.0003$ respectively).

The patients with a moderate depressive episode predominated in the group with PDR $(45.92 \pm 3.48) \%$ and BAD $(43.97 \pm 2.35) \%$ than in the group with with RDD $(36.59 \%$, DC $=0.99, \mathrm{MI}=0.05, \mathrm{p}<0.041$ and $\mathrm{DC}=0.80, \mathrm{MI}$ $=0.03, \mathrm{p}<0.047$, respectively).

The study analyzed in more detail the features of manifestation of depressive disorders in patients with $\mathrm{CI}$ at different types of depression (Fig. 3). Thus, according to MADRS, it was determined that in patients with RDD the most pronounced depressive manifestations were impaired concentration $(5.89 \pm 2.05$ points $)$, subjective and objective signs of depression (5.88 \pm 2.11 and $5.67 \pm 2.09$ points, respectively), 


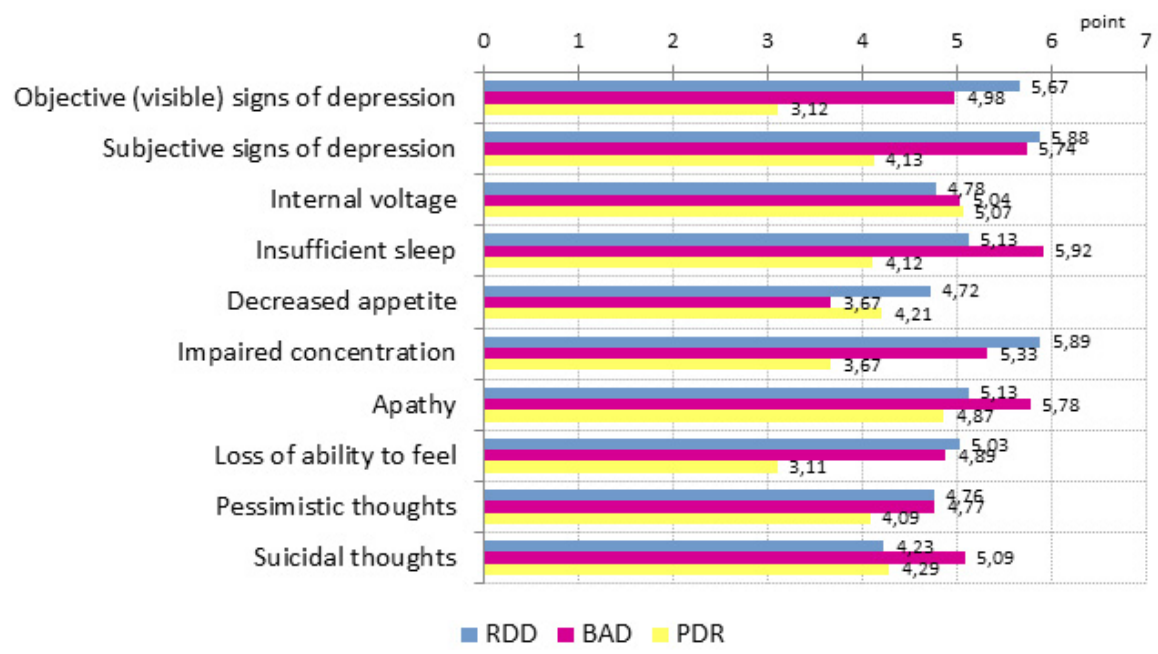

Fig. 3. Features of depressive manifestations in patients with cognitive impairment at depressive disorders (according to the MADRS scale)

apathy ( $5.13 \pm 2.42$ points) and loss of ability to feel $(5.03 \pm 3.07$ points $)$. In patients with BAD, the most pronounced manifestations of depressive disorders were insufficient sleep $(5.92 \pm 2.89$ points), apathy (5.78 \pm 3.06 points), subjective signs of depression (5.74 \pm 3.11 points), impaired concentration (5.33 \pm 2.86 points) and suicidal thoughts $(5.09 \pm 3.06$ points $)$. In patients with PDR depressive manifestations were expressed primarily by the presence of internal stress $(5.07$ \pm 1.77 points), apathy ( $4.87 \pm 1.46$ points), suicidal thoughts $(4.29 \pm 2.46$ points $)$ and decreased appetite (4.21 \pm 1.80 points).

Statistical analysis of the results revealed that the patients with RDD and BAD differed from those with PDR by greater severity of such depressive manifestations as subjective (5.88 \pm 2.11 points, $\mathrm{p}<0.005$ and $5.74 \pm 3.11$ points, $\mathrm{p}<$ 0.0025 , respectively) and objective $(5.67 \pm 2.09$ points, $\mathrm{p}<0.001$ and $4.98 \pm 3.08$ points, $\mathrm{p}<0.0025$, respectively) signs of depression, more pronounced sleep disturbances $(5.13 \pm 2.02$ points, $\mathrm{p}<0.025$ and $5.92 \pm 2.89$ points, $\mathrm{p}<0.001$, respectively), decreased concentration (5.89 \pm 2.05 points, $\mathrm{p}<0.0001$ and $5.33 \pm 2.86$ points, $p$ $<0.005$, respectively) and loss of ability to feel $(5.03 \pm 3.07$ points, $\mathrm{p}<0.01$ and $4.89 \pm 2.03$ points, $\mathrm{p}<0.025$, respectively). It was also found that the decrease in appetite was more pronounced in patients with RDD $(4.72 \pm 1.87)$ than in patients with $\operatorname{BAD}(3.67 \pm 1.94$ points, $p<0,043)$.

According to numerous studies, the presence of depressive disorders is associated with the pathomorphosis of mental disorders, tendencies to somatization with complex autonomic and visceral disorders and maladaptation of patients $[4,5]$. The obtained results coincide with the literature data and indicate that depressive disorders in patients with cognitive impairments have a complex syndromal structure, which differs depending on the type of depressive disorder. The obtained data will help to expand the scientific understanding of the syndromal characteristics of depressive manifestations in patients with cognitive impairment in depressive disorders and to improve the strategy of providing treatment and rehabilitation care to patients with depression.

\section{Conclusions}

Our findings demonstrate that:

- in patients with RDD, a combination of apathetic-dynamic (27.64\%), astheno-energetic $(26.83 \%, \mathrm{p}<0.05)$, anxiety $(13.01 \%)$ symptom complexes; predominance of moderate and major depressive episodes $(36.59 \%$ and $34.96 \%$, respectively); predominance of the following clinical signs of depression: apathy (5.13 points), subjective and objective signs of depression (5.86 and 5.67 points, respectively), decreased concentration (5.89 points), loss of ability to feel (5 .03 points) can be determined;

- in patients with BAD, a combination of astheno-energetic $(25.53 \%, \mathrm{p}<0.05)$, apatheticdynamic $(24.82 \%)$, melancholic $(17.02 \%, \mathrm{p}<0.05)$ symptom complexes; predominance of moderate and major depressive episodes ( $43.97 \%$ and $28.37 \%$, respectively); predominance of the following clinical signs of depression: apathy (5.78 points), subjective signs of depression (5.74 points), suicidal thoughts (5.09 points), sleep disturbances (5.92 points), decreased concentration (5.33 points) can be determined;

- in patients with PDR, a combination of anxiety $(59.18 \%, \mathrm{p}<0.05)$, apathetic-adynamic $(23.47 \%)$ 
symptom complexes; predominance of moderate and minor depressive episodes $(45.92 \%$ and $43.88 \%$, respectively); predominance of the following clinical signs of depression: internal tension (5.07 points), apathy (4.87 points), suicidal thoughts (4.29 points), loss of appetite (4.21 points) can be determined.
Thus, the study identified clinical and psychopathological features of depressive manifestations and leading symptom complexes in patients with $\mathrm{CI}$ in different types of DD, which can be used as diagnostic criteria and should be considered at implementation of psychocorrectional and rehabilitation measures.

\section{References:}

1. Comprehensive mental health action plan 2013-2020 (2013). [Electronic resource]. Geneva: WHO, 2013. Mode of access: http://apps.who.int/gb/ebwha/pdf_files/WHA66/A66_R8-ru.pdf?ua=1 (Russian)

2. Eschweiler G. W. (2017) Diagnostik und multimodale Therapie der Altersdepression: Diagnostics and multimodal treatment of depression in old age. Zeitschrift fur Gerontologie und Geriatrie. 50: 2; 99105. DOI: $10.1007 / \mathrm{s} 00391-016-1174-2$.

3. Maslow G.R., Dunlap K., Chung R. J. (2015) Depression and Suicide in Children and Adolescents. Pediatr Rev.: 36 (7); 299-308; quiz 9-10. Epub 2015/07/03. DOI: 10.1542/pir. 36-7-299.

4. McIntyre RS, Lophaven S, Olsen CK. (2014) A randomized, double-blind, placebo-controlled study of vortioxetine on cognitive function in depressed adults. Int J Neuropsychopharmacol, 17(10): 1557-67.

5. Maruta N.O., Panko T.V. Kalenska G.Yu. (2017) Diagnostic criteria for depressive disorders at stages of providing medical aid. Ukrainian Newsletter of Psychoneurology., 25: 1 (90): 135. (Ukranian)

6. Cotrena, C., Branco, L. D., Shansis, F. M. \& Fonseca, R. P. (2016) Executive function impairments in depression and bipolar disorder: association with functional impairment and quality of life. J. Affect. Disord. 190, 744-753.

7. Olvet, D. M., Klein, D. N. \& Hajcak, G. (2010) Depression symptom severity and errorrelated brain activity. Psychiatry Res. 179, 30-37.

8. Snyder, H. R. (2013) Major depressive disorder is associated with broad impairments on neuropsychological measures of executive function: a meta-analysis and review. Psychological Bull. $139,81-132$.

9. Practice Guideline for the treatment of patients with major depressive disorder. 3rd ed. Arlington, VA: American Psychiatric Association, 2010.

10.McIntyre R.S., Cha D.S., Soczynska J.K. et al. (2013) Cognitive deficits and functional outcomes in major depressive disorder: determinants, substrates, and treatment interventions. Depress. Anxiety, $30(6) ; 515-527$.

11. Zuckerman, H. et al. (2018) Recognition and treatment of cognitive dysfunction in major depressive disorder. Front. Psychiatry 9; 655.

12. McKnight P.E., Kashdan T.B. (2009) The importance of functional impairment to mental health outcomes: a case for reassessing our goals in depression treatment research. Clin. Psychol. Rev., 29(3); $243-259$.

13. Montgomery SA, Asberg M. (1979) A new depression scale designed to be sensitive to change. $\mathrm{Br}$ J. Psychiatry. 134: 382-389.

Received: 21-Jul-2020

Accepted: 18-Sep-2020 